\title{
http://bjas.journals.ekb.eg \\ The Effects of Alveolar Recruitment Maneuver Versus Low Tidal Volume Ventilation on Oxygenation and Lung Mechanics in Patients Undergoing Laparoscopic Surgeries: A Prospective Randomized Controlled Study
}

\author{
M.B.Hassanein, A.M.Abdel-Hamid, A.A.Mosaad and N.S.Ibrahim \\ Anaesthia Dept., Faculty of Medicine, Benha Univ., Benha, Egypt \\ E-Mail: nadersaadn@gmail.com
}

\begin{abstract}
Different ventilatory strategies have been studied to improve gas exchange and compliance of the lungs in patients undergoing laparoscopic surgeries. This study aimed to test the impact of alveolar recruitment maneuver versus low tidal volume ventilation combine with PEEP on arterial oxygenation and lung mechanics in patients undergoing laparoscopic surgeries. Sixty patients were randomly allocated into three equal groups according to the type of ventilation strategy used during surgery. In the control group, patients received conventional volume-controlled ventilation with $10 \mathrm{ml} / \mathrm{Kg} \mathrm{V}$ T and zero PEEP (ZEEP). In group II ( LTV ), patients received low tidal volume ventilation in the form of $6-8 \mathrm{ml} / \mathrm{Kg} \mathrm{V} \mathrm{V}_{\mathrm{T}}$ and PEEP $5 \mathrm{cmH}_{2} \mathrm{O}$. In group III (REC), patients received 6-8 ml/ $\mathrm{Kg}$ and recruitment maneuvers were done every 10 minutes after intubation till extubation by manual inflation to $40 \mathrm{cmH}_{2} \mathrm{O}$ peak inspiratory pressure for 15 seconds then the patient was placed back to the same ventilation settings with PEEP of $5 \mathrm{cmH}_{2} \mathrm{O}$. The primary outcome is the dynamic compliance. The secondary outcome measures include $\mathrm{PaO}_{2}, \mathrm{PH}, \mathrm{PCO} 2$, $\mathrm{SPO}_{2}, \mathrm{HR}$ and MAP. Demographic characteristics and duration of surgery were comparable among groups. $\mathrm{PaO}_{2}$ was highly significantly increased $(p<0.001)$ in the recruitment group (Rec) compared to the conventional group $(C)$ and low tidal volume ventilation group (LTV). There was significant increase in dynamic compliance in the recruitment group (REC) compared with the conventional (C) and low tidal volume (LTV) groups. $\mathrm{SpO}_{2}, \mathrm{PaCO}_{2}$ showed a highly statistical significance differences between the three ventilated groups. There were no statistically significant differences between the three ventilated groups in terms of PH. There were no statistically significant differences between the three ventilated groups in terms of Mean arterial blood pressure and HR. repeated recruitment maneuvers combined with $5 \mathrm{~cm} \mathrm{H}_{2} \mathrm{O}$ of PEEP increased respiratory system compliance and $\mathrm{Pa}_{\mathrm{O} 2}$ in patients undergoing laparoscopic surgeries without hemodynamics adverse effects.
\end{abstract}

Keywords: Recruitment Maneuver, Low tidal volume ventilation, Oxygenation, Compliance.

\section{Introduction}

Respiratory function is impaired in patients undergoing laparoscopic surgeries. This is due to the combined effects of the supine position, muscle paralysis and pneumoperitoneum on lung function, in the form of reducing the functional residual capacity, increasing the closing volume and consequent atelectasis. As a result, there is impairement in lung compliance and gas exchange [1].

Different ventilatory strategies have been studied to improve gas exchange and compliance of the lungs in these patients including large tidal volume, high frequency ventilation, low tidal volume with PEEP and reverse Trendelenburg position; however, the effects of these strategies have been variable [2] . Moreover, alveolar recruitment maneuver using inspiratory pressure of $40 \mathrm{~cm} \mathrm{H} 2 \mathrm{O}$ sustained for 15 seconds followed by PEEP $8 \mathrm{~cm} \mathrm{H} 2 \mathrm{O}$ has been shown to improve intraoperative arterial oxygenation in open bariatric surgery as studied [3].

However, the effectiveness of recruitment maneuver neither the low tidal volume ventilation with PEEP has been demonstrated in normal low risk patients undergoing minor and short laparoscopic surgeries. In addition, a good response in this low-risk population to the recruitment maneuver would suggest that further investigations of the postoperative risks and benefits of the maneuver are needed, particularly for patients with lungs that are prone to collapse such as upper abdominal, thoracic and lengthy laparoscopic surgeries.

In this study, we tested the impact of alveolar recruitment maneuver versus low tidal volume ventilation combine with PEEP on arterial oxygenation and lung mechanics in patients undergoing simple laparoscopic surgeries. Also, the frequency and extent of haemodynamic changes together with arterial blood gases were monitored.

\section{Patients and methods}

This study was conducted in the faculty of medicine of Benha University from May 2017 till August 2019. After obataining approval by the Benha University Hospital Ethics Committee, and written informed consent from the patient, 60 ASA physical status I-II patients were studied and scheduled for elective laparoscopic surgeries (cholecystectomy, ovarian cysts, and inguinal hernias) in a randomized, single-blind, clinical trial.

Randomization was done by an online program, which was used to generate a random number list. Patients randomization numbers were concealed in opaque envelops, which were opened by the investigator. The staff members providing postoperative care were blinded to group assignment.

Patients were randomly allocated into three equal groups according to the type of ventilation strategy used during surgery, each group consisted of twenty patients: 


\section{- Group I (C) patients received conventional volume- controlled ventilation with $10 \mathrm{ml} / \mathrm{Kg}$ VT and zero PEEP (ZEEP).}

- Group II (LTV) patients received low tidal volume ventilation in the form of $6-8 \mathrm{ml} / \mathrm{Kg}$ VT and PEEP $5 \mathrm{cmH} 2 \mathrm{O}$.

- Group III (REC) patients received 6-8 $\mathrm{ml} / \mathrm{Kg}$ and recruitement maneuvers were done every 10 minutes after intubation till extubation by manual inflation to $40 \mathrm{cmH} 2 \mathrm{O}$ peak inspiratory pressure for 15 seconds then the patient was placed back to the same ventilation settings with PEEP of $5 \mathrm{cmH} 2 \mathrm{O}$.

All patients were asked to fast $8 \mathrm{hrs}$ before operation. Intravenous cannula was inserted and the patients were premedicated with midazolam $0.01 \mathrm{mg} / \mathrm{Kg}$ i.v., $30 \mathrm{~min}$ preoperatively, while patients were lying on a semisitting position on oxygen mask.

On admission to the operating room, routine monitors (pulse oximeter, E.C.G., and non-invasive blood pressure) were connected and baseline measurements $(\mathrm{SpO} 2$, heart rate, and mean arterial blood pressure) were recorded, and then arterial cannula was inserted in the radial artery of the nondominant hand under local anaesthesia after performing modified Allen's test to facilitate serial blood gases sampling.

Before induction, pre-oxygenation with $100 \%$ oxygen was done, anaesthesia was induced by propofol $2.5 \mathrm{mg} / \mathrm{Kg}$, fentanyl $1-2 \mu \mathrm{g} / \mathrm{Kg}$, intubation was facilitated by atracurium $0.5 \mathrm{mg} / \mathrm{Kg}$ and anaesthesia was maintained with Isoflurane $1.5-2 \%$. Increments of atracurium (10 mg) were given to maintain muscle relaxation whenever needed. Neostigmine $0.04-0.08 \mathrm{mg} / \mathrm{Kg}$, together with atropine 0.01-0.02 $\mathrm{mg} / \mathrm{Kg}$ were given when extubation criteria were met.

\subsection{Exclusion criteria}

Patients having any respiratory diseases whether obstructive or restrictive, pre-existing cardiac diseases, spontaneous pneumothorax history, heavy smoking history, BMI $\geq 30 \mathrm{Kg} / \mathrm{m} 2$, age more than 60 and less than 20 were excluded from the study.

\subsection{Parameters of assessment}

The primary outcome is the dynamic compliance which was measured right after induction and intubation as a baseline, 5 minutes before insufflation, and again 5 minutes after desufflation before extubation by getting the following parameters from the ventilator which are the PIP,PEEP and the Vt, and by using the following equation, Compliance $=\mathrm{Vt} /$ (PIP-PEEP).

Also, the oxygenation was studied by measuring the $\mathrm{pO} 2$ at room air before induction as a baseline then after induction before insufflation, after desufflation and 30 minutes after recovery in the immediate post operative period.

The secondary outcome measures included $\mathrm{PH}$, $\mathrm{PCO} 2, \mathrm{SpO} 2$ which were taken preoperatively at baseline, and before insufflation, after desufflation and $30 \mathrm{~min}$ after recovery.

Furthermore, the HR and mean arterial blood pressure were measured preoperatively at baseline, and every $10 \mathrm{~min}$ since intubation till extubation.

\subsection{Statistical analysis}

Statistical analysis were performed using a standard statistical program (SPSS, version 16; SPSS Inc., Chicago, Illinois, USA). Quantitative data were presented as mean \pm SD. Qualitative data were presented as numbers and percentages. Quantitative data were analysed by using ANOVA test, significant ANOVA tests were further analyzed by post-hoc analysis (Bonferroni correction) to detect significant group. Qualitative data were analysed by using X2 test and $\mathrm{Z}$ test. $P$ value less than 0.05 was considered statistically significant and $P$ value less than 0.01 was considered highly statistically significant.

\section{Results}

There were no statistically significant differences between the three ventilated groups in terms of age, weight, height, gender, American Society of Anaesthesiologists physical status classification system, BMI and duration of surgery $(p>0.05)$ Table (1).

There were high statistically significant differences between the three ventilated groups regarding the $\mathrm{PaO} 25$ minutes before insufflation, 5 minutes after desufflation and 30 minutes after recovery. In addition, the post hoc test revealed that $\mathrm{PaO} 2$ was highly significantly increased $(p<0.001)$ in the recruitment group (Rec) compared to the conventional group (C) and low tidal volume ventilation group (LTV) at 5 minutes before insufflation, 5 minutes after desufflation and 30 minutes after recovery. Moreover; there were statistically significant increase regards $\mathrm{PaO} 2$ in group LTV compared to group $\mathrm{C}$ considering the $\mathrm{PaO} 25$ minutes after desufflation only. Table (2).

There were statistical significance differences between the three ventilated groups regarding the dynamic compliance 5 minutes before insufflation, 5 minutes after desufflation. In addition, the post hoc test revealed that there were significant increase in compliance in the recruitment group (REC) compared with the conventional (C) and low tidal volume (LTV) groups in 5 minutes before insufflation and 5 minutes after desufflation Table (3) .

There were high statistical significance differences between the three ventilated groups regarding the $\mathrm{SpO} 25$ minutes before insufflation, 5 minutes after desufflation and 30 minutes after recovery. In addition, the post hoc test revealed that there were significant statistically differences between group Rec and group $\mathrm{C}$ considering the $\mathrm{SpO} 25$ minutes before insufflation, 5 minutes after desufflation and 30 minutes after recovery. Also, there were significant statistically differences between group Rec and group LTV considering $\mathrm{SpO} 25$ minutes before insufflation, 5 minutes after desufflation and 30 minutes after 
recovery. Moreover; there were significant statistically differences between group LTV and group C considering the SpO2 5 minutes after desufflation.Fig (1).

There were no statistical significant differences between the three ventilated groups in terms of $\mathrm{PaCO} 2$ pre-operative baseline, 5 minutes before insufflation, 5 minutes after desufflation and 30 minutes after recovery in the immediate post-operative period $(p>0.05)$ Fig (2).

There were no statistical significant differences between the three ventilated groups in terms of $\mathrm{PH}$ pre-operative baseline, 5 minutes before insufflation, 5 minutes after desufflation and 30 minutes after recovery in the immediate post-operative period ( $p$ $>0.05)$ Fig (3).

There were no statistical significant differences between the three ventilated groups in terms of Mean arterial blood pressure pre-operative baseline, after 10 minutes, 20 minutes, 30 minutes, 40 minutes, 50 minutes and 60 minutes $(p>0.05)$ Fig (4).

There were no statistically significant differences between the three ventilated groups groups in terms of Heart rate pre-operative baseline, after 10 minutes, 20 minutes, 30 minutes, 40 minutes, 50 minutes and 60 minutes $(p>0.05)$. Fig (5).

Table (1) Demographic data and duration of surgery

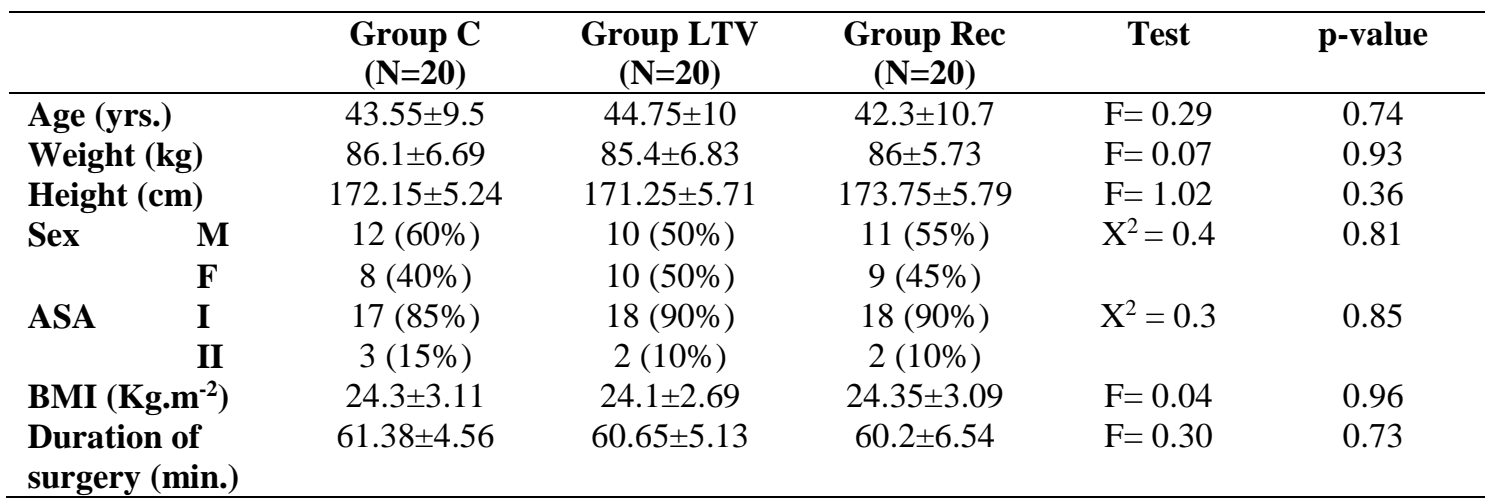

Data were presented as mean \pm SD except for sex and ASA were presented as number (\%)

Table (2) Peri-operative arterial oxygen tension

\begin{tabular}{|c|c|c|c|c|c|}
\hline $\mathrm{PaO}_{2}(\mathrm{mmHg})$ & $\begin{array}{c}\text { Group C } \\
(\mathrm{N}=\mathbf{2 0})\end{array}$ & $\begin{array}{c}\text { Group LTV } \\
(\mathrm{N}=\mathbf{2 0})\end{array}$ & $\begin{array}{c}\text { Group Rec } \\
(\mathbf{N}=\mathbf{2 0})\end{array}$ & F value & p-value \\
\hline Baseline pre-op & $94.9 \pm 5.31$ & $95.1 \pm 4.36$ & $95.3 \pm 5.02$ & 0.07 & 0.92 \\
\hline $5 \mathrm{~min}$. before insuff. & $427 \pm 31.14$ & $440 \pm 29.30$ & $486 \pm 11.99+9$ & 28.8 & $<0.001 * *$ \\
\hline 5 min. after disuff. & $372 \pm 27.31$ & $393 \pm 27.16 \#$ & $437 \pm 13.12+9$ & 39.8 & $<0.001 * *$ \\
\hline $\begin{array}{l}30 \text { min. after } \\
\text { recovery }\end{array}$ & $96 \pm 0.65$ & $96.2 \pm 0.62$ & $98.8 \pm 0.61 \dagger \mathbf{q}$ & 146.08 & $<0.001 * *$ \\
\hline
\end{tabular}

Data were presented as mean \pm SD $* *$ Highly significant $\uparrow$ Significance between Group Rec and Group C\# Significance between Group LTV and Group C II Significance between Group Rec and Group LTV

Table (3) Intra-operative dynamic lung compliance

\begin{tabular}{lccccc}
\hline $\begin{array}{l}\text { Dynamic Compliance } \\
(\mathbf{c m H} \mathbf{O})\end{array}$ & $\begin{array}{c}\text { Group C } \\
(\mathbf{N}=\mathbf{2 0})\end{array}$ & $\begin{array}{c}\text { Group LTV } \\
\mathbf{( N = 2 0 )}\end{array}$ & $\begin{array}{c}\text { Group Rec } \\
(\mathbf{N}=\mathbf{2 0})\end{array}$ & F value & $p$-value \\
\hline $\begin{array}{l}\text { Baseline after } \\
\text { intubation. }\end{array}$ & $74.62 \pm 16.11$ & $74.35 \pm 16.48$ & $74.15 \pm 15.6$ & 0.004 & 0.99 \\
$\mathbf{5}$ min. before insuff & $73.6 \pm 15.2$ & $74.2 \pm 16.3$ & $84.35 \pm 9.49 \dagger \boldsymbol{\Phi}$ & 3.82 & $0.02 *$ \\
$\mathbf{5}$ min. after disuff. & $45.7 \pm 9.39$ & $49.95 \pm 6.32$ & $69.76 \pm 6.50 \dagger \boldsymbol{\Phi}$ & 61.2 & $<0.001 * *$ \\
\hline
\end{tabular}

Data were presented as mean \pm SD

*Significant

**Highly significant

$\uparrow$ Significance between Group Rec and Group C

II Significance between Group Rec and Group LTV 


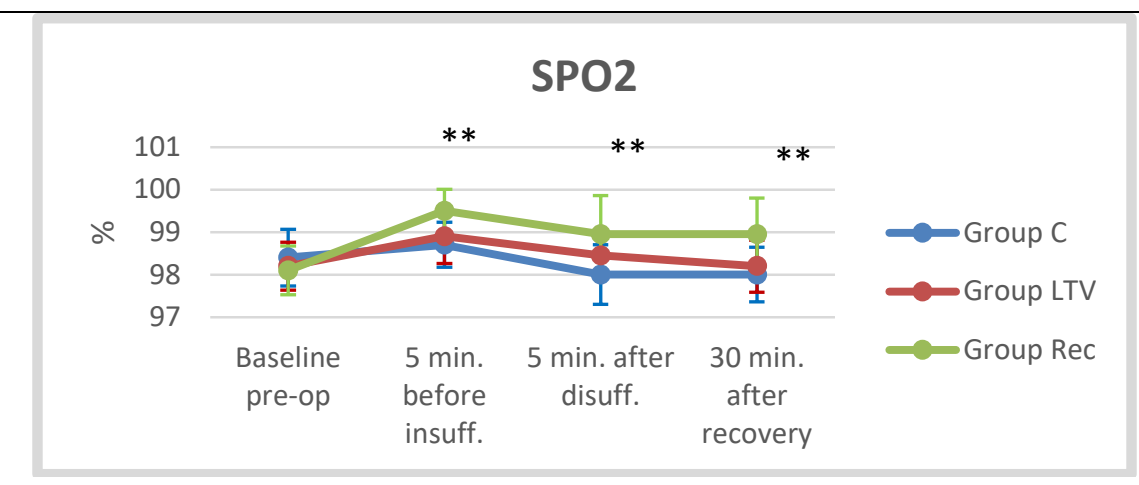

Fig (1) Peri-operative $\mathrm{SpO}_{2}$

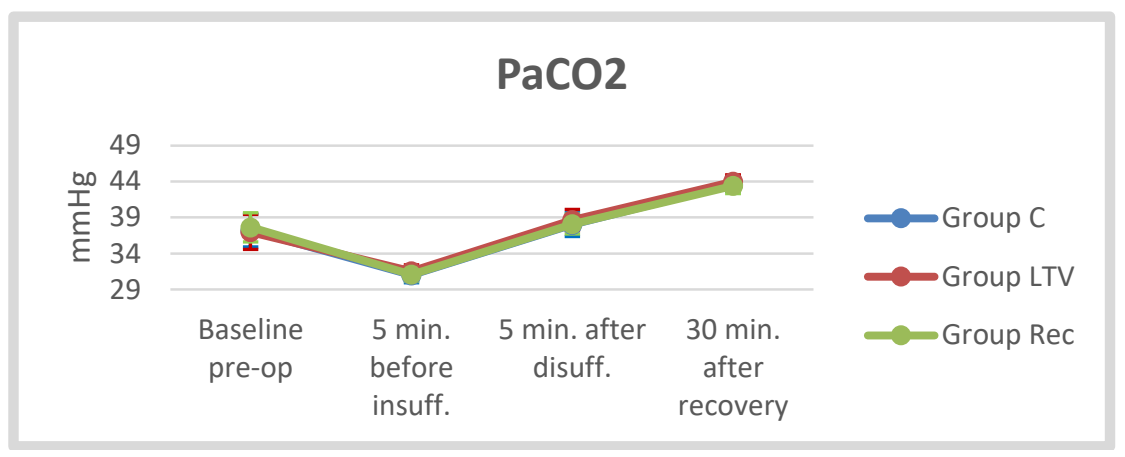

Fig (2) Peri-operative $\mathrm{PCO}_{2}$

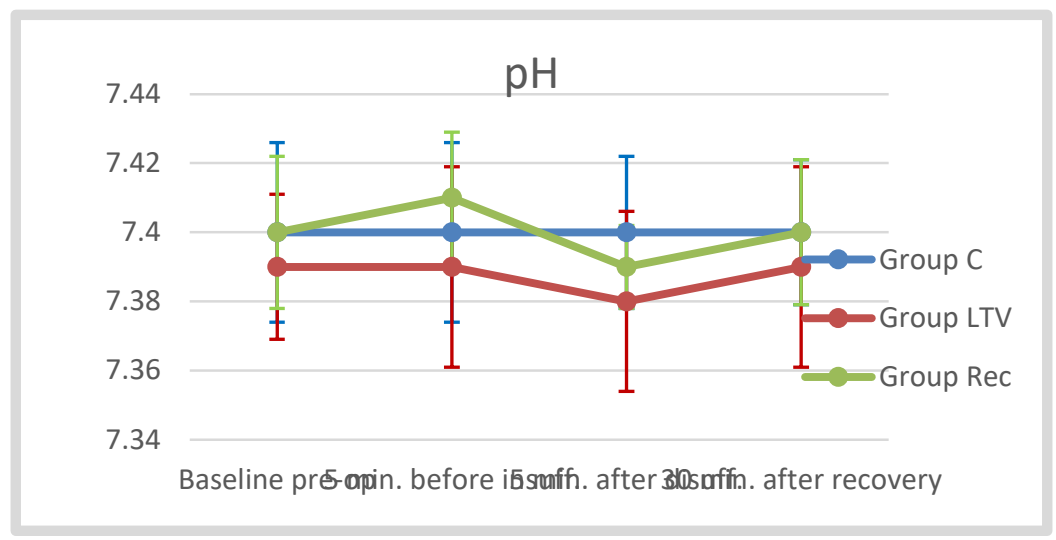

Fig (3) Peri-operative $\mathrm{pH}$

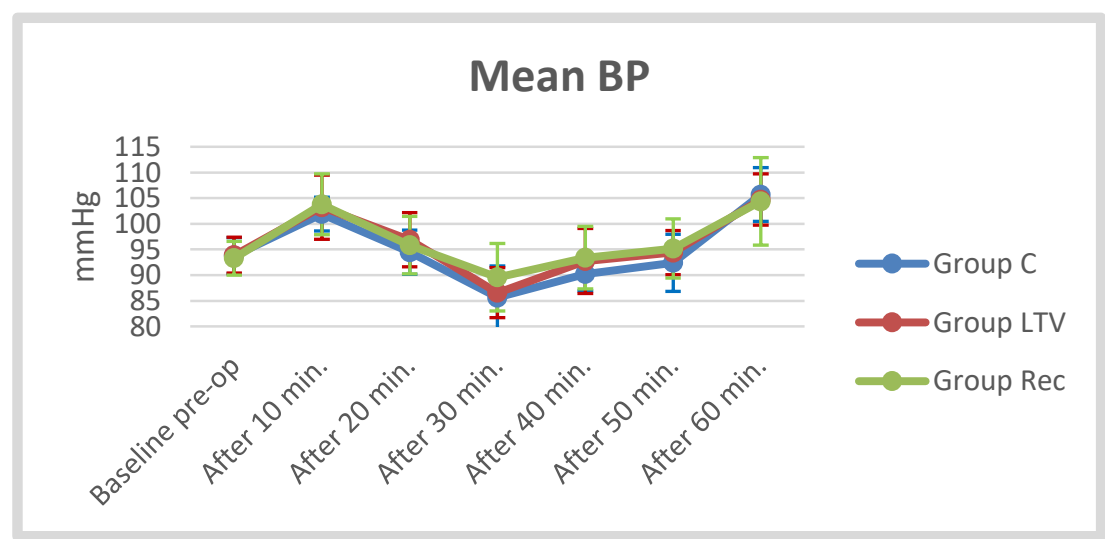

Fig (4) Pre and intra-operative mean arterial blood pressure 


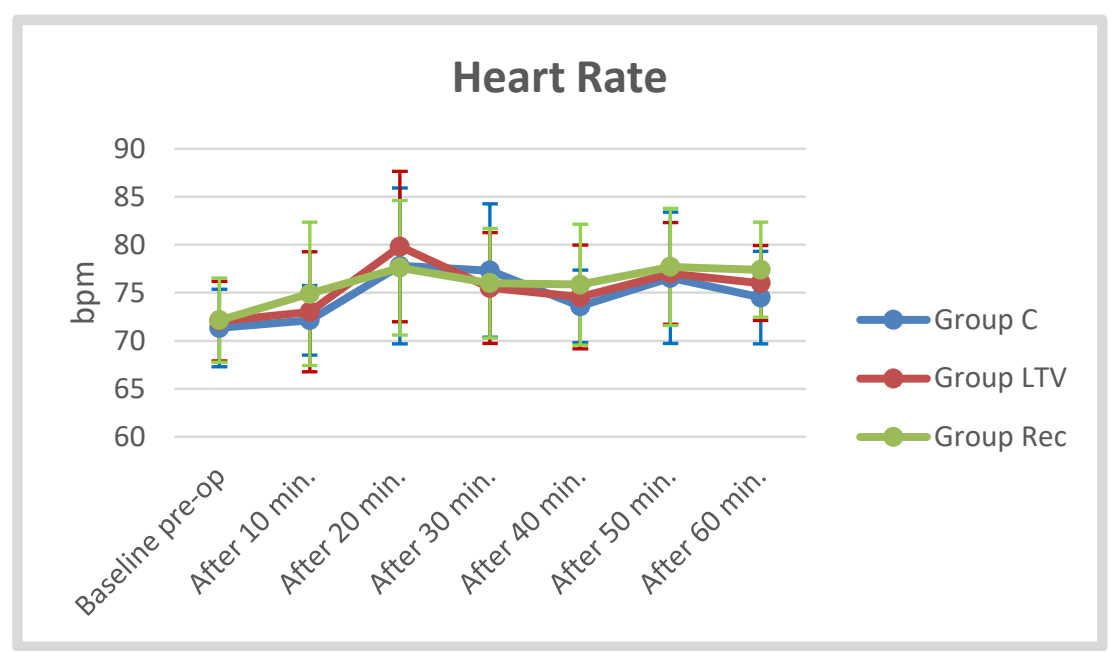

Fig (5) Pre and intra-operative heart rate

\section{Discussion}

In the present study, we compared the effects of alveolar recruitment maneuver versus the effects of low tidal volume ventilation with PEEP on the arterial oxygenation and dynamic lung compliance in patients undergoing laparoscopic surgeries.

Lung recruitment using inspiratory pressure of 40 $\mathrm{cmH} 2 \mathrm{O}$ for 15 seconds and combined with PEEP of 5 $\mathrm{cm} \mathrm{H} 2 \mathrm{O}$ was associated with the best respiratory system compliance and best $\mathrm{PaO} 2$ in patients undergoing laparoscopic surgeries, however, the use of low tidal volume ventilation with PEEP alone did not have the same effect on oxygenation and lung compliance. The increase in arterial oxygenation after the recruitment maneuver suggests a reversal of anaesthesia-induced atelectasis and the ventilation/perfusion mismatch. These results are in keeping with the concept of 'opening up the lung and keeping it open' by alveolar recruitment achieved via a high inspiratory pressure maneuver with alveolar derecruitment minimized by applying PEEP.

Overall, there were no statistically significant differences as regards the heamodynamics (mean arterial blood pressure and heart rate) and blood gases ( $\mathrm{pH}$ and $\mathrm{PCO} 2$ ) in comparison to the control group (conventional) and the low tidal volume ventilation group (LTV).

Dynamic pulmonary compliance is one of the best methods for determining the effectiveness of Alveolar Recruitment Maneuvers besides obtaining an arterial blood gas and calculating the P (A-a) O2. In addition, it is a more practical and less invasive approach. Dynamic pulmonary compliance is calculated by dividing the tidal volume ( $\mathrm{Vt}$ ) by the difference between the peak inspiratory pressure ( PIP ) and the positive end-expiratory pressure (PEEP): dynamic compliance $=\mathrm{Vt} /(\mathrm{PIP}-\mathrm{PEEP})$. An increase in pulmonary compliance immediately following the application of an alveolar recruitment maneuver would presumably reflect a reduction in atelectasis and result in an increase in $\mathrm{PaO} 2$ due to better matching of ventilation and perfusion. In addition, a more clinically relevant method for determining whether an increase in compliance has occurred can be utilized to avoid the need to perform the above calculations. During volume control continuous mandatory ventilation, the provider would note that the same $\mathrm{Vt}$ is delivered at a lower PIP following application of alveolar recruitment maneuvers. With pressure control continuous mandatory ventilation, the provider would note that an increased $\mathrm{Vt}$ is delivered at the same inspiratory pressure setting. Moreover, contemporary anaesthesia ventilators often include options to display the pressure-volume loop and calculated dynamic compliance values, making it even easier to measure the effectiveness of alveolar recruitment maneuvers.

Our findings are in a agree with the results of [4] who conducted a comparative study between the effects of four intraoperative ventilatory strategies on respiratory compliance and gas exchange during laparoscopic gastric banding in obese patients. And concluded that repeated alveolar recruitement maneuver every 10 minutes, using inspiratory pressure of $40 \mathrm{~cm} \mathrm{H} 2 \mathrm{O}$ for 15 seconds, followed by PEEP 10 $\mathrm{cm} \mathrm{H} 2 \mathrm{O}$ had increased the respiratory system compliance and $\mathrm{PaO} 2$ without adverse events. Moreover, the beneficial effects on oxygenation continued into the early recovery period.

Also, FX. Whalen et al,. [5] conducted a study on the effects of alveolar recruitment maneuver and positive end-expiratory pressure on arterial oxygenation during laparoscopic bariatric surgery, which revealed an increase in intraoperative $\mathrm{PaO} 2$ and pulmonary compliance in the alveolar recruitment maneuver group.

CK. Pang ET AL., [6] studied the effect of an alveolar recruitment strategy on oxygenation in laparoscopic cholecystectomy and reported an increase 
in intraoperative $\mathrm{PaO} 2$ but did not include pulmonary compliance in their research.

TN. Weingarten ET AL., [7] studied the effects of recruitment maneuver during ventilation of elderly patients undergoing major open abdominal surgeries. They found that the recruitment group had improved breathing mechanics as evidenced by increased dynamic compliance (36\%), and decreased airway resistance $(21 \%)$, and concluded that lung recruitment strategy improves intraoperative oxygenation and lung mechanics during laparotomy, which agrees with our results.

Moreover, Fumagalli [8]conducted a study on lung recruitment in obese patients with acute respiratory distress syndrome, and found that performing a recruitment maneuver followed by applying PEEP according to the PEEPDECREMENTAL trial obtained the best lung function by decreasing lung over distension and collapse, and restoring lung elastance and oxygenation.

Concerning the choice of the type of the recruitment maneuver used [4,6] utilized sustained manual inflations to a PIP of $40 \mathrm{~cm} \mathrm{H} 2 \mathrm{O}$ for their alveolar recruitment maneuvers [4] utilized single sustained manual inflations for 15 seconds, whereas Pang et al.6 utilized 10 sustained manual inflations over 1 minute. Both studies found an increase in intraoperative $\mathrm{PaO} 2$ in the alveolar recruitment maneuver groups. However, only WA .Almarakbi et al., [4] reported on pulmonary compliance, which showed an increase exclusively in the alveolar recruitment maneuver groups. [7,9 and5] utilized stepwise increases in PEEP starting at $4 \mathrm{~cm} \mathrm{H} 2 \mathrm{O}$ and ending at $20 \mathrm{~cm} \mathrm{H} 2 \mathrm{O}$ as alveolar recruitment maneuvers. Weingarten et al. and Whalen et al.7,5 included intraoperative $\mathrm{PaO} 2$ in their studies and there was a statistically significant increase in the alveolar recruitment maneuver groups. [7,9 and 5] Also showed an improvement in pulmonary compliance in the alveolar recruitment maneuver groups in the intraoperative period.

In this study, lung recruitment using sustained manual inflations to an inspiratory pressure of 40 cmH2O for 15 seconds every 10 minutes and followed by PEEP of $5 \mathrm{~cm} \mathrm{H} 2 \mathrm{O}$ was used and was associated with the best respiratory system dynamic compliance and best $\mathrm{PaO} 2$ in the recruitment maneuver group.

Overall, the different types of alveolar recruitment maneuvers were found to be equally effective. It's important to note that, manual sustained hyperinflations are more easy and practical to use and require a shorter amount of time to perform, while stepwise increases in PEEP or $\mathrm{Vt}$ may prevent untoward subject responses such as straining or coughing when the depth of anaesthesia is equivocal.

Moreover, concerning how long alveolar maneuvers should be held to be effective, the time that the manual alveolar recruitment maneuver is held to a set PIP varies in different studies. [10,11,12 and 13] considered inflation of the lungs for 5-30 seconds to a prescribed PIP as representative of alveolar recruitment maneuvers. (4) held alveolar recruitment maneuvers for 15 seconds while Pang et al. 6 did not specify a period of time for holding the alveolar recruitment maneuver, they utilized 10 alveolar recruitment maneuvers over 1 minute, which leaves, at best, a few seconds for an inspiratory hold if it indeed was utilized. On the other hand, [7,9 and 5] involving stepwise increases in PEEP all performed them in the same manner. Subjects received 3 breaths when the PEEP was increased from 4 to $10 \mathrm{~cm} \mathrm{H} 2 \mathrm{O}$, then received 3 breaths when the PEEP was increased from 10 to $15 \mathrm{~cm} \mathrm{H} 2 \mathrm{O}$, and finally 10 breaths when the PEEP was increased to $20 \mathrm{~cm} \mathrm{H} 2 \mathrm{O}$.

In addition, P. Severgnini et al., [14] defined an alveolar recruitment maneuver as setting PIP to $45 \mathrm{~cm}$ $\mathrm{H} 2 \mathrm{O}$ with an inspiratory/expiratory ratio of $3: 1$. The $\mathrm{Vt}$ was then increased in steps of $4 \mathrm{~mL} / \mathrm{Kg}$ of ideal body weight until a plateau pressure of $30 \mathrm{~cm} \mathrm{H} 2 \mathrm{O}$ was reached, at which time 3 breaths were given.

As for the use of repeated alveolar recruitment maneuver rather than single maneuver, the study conducted by [4] was the only study to measure the effect of different frequencies of alveolar recruitment maneuvers. One of the experimental groups received an alveolar recruitment maneuver once, whereas another received alveolar recruitment maneuvers every 10 minutes until completion of surgery. The repeated alveolar recruitment maneuver group showed the greatest improvement in intraoperative $\mathrm{PaO} 2$, pulmonary compliance, and postoperative $\mathrm{PaO} 2$. It was noted that the benefit of an elevated $\mathrm{PaO} 2$ in the single alveolar recruitment maneuver group was temporary, whereas the benefit was sustained in the repeated alveolar recruitment maneuver group.

It is important to note that, [4] studied the differences in the utilization of PEEP following an alveolar recruitment maneuver and there was a significant advantage in compliance, intraoperative and postoperative $\mathrm{PaO} 2$ in the alveolar recruitment maneuver groups followed by PEEP.

As regards the effects of different ventilator strategies used in this study on heamodynamics, there was no statistically significant difference in the heamodynamics in the form of mean arterial blood pressure and heart rate between the three groups. This agrees with [15] who studied the effects of alveolar recruitment strategy on arterial oxygenation and heamodynamics during general anaesthesia who concluded that heart rate, systolic and diastolic pressures were within normal range during the study.

In contrast, FX. Whalen et al., [5] studied the effects of alveolar recruitment maneuver during laparoscopic bariatric surgery using peak inspiratory pressures up to $50 \mathrm{~cm} \mathrm{H} 2 \mathrm{O}$ followed by positive end expiratory pressure of $12 \mathrm{~cm} \mathrm{H} 2 \mathrm{O}$ and observed hypotension and increased requirement of vasopressors. However, this complication was not observed in this study that could be explained, by the 
relatively lower peak inspiratory pressure and positive end expiratory pressure used during the study.

Concerning the $\mathrm{pH}$ and $\mathrm{PaCO} 2$, both remained in the normal range and showed no significant differences between groups, which agrees with [16], who studied the effect of alveolar recruitment maneuver and positive end expiratory pressure on arterial oxygenation and postoperative outcome in morbidly obese patients undergoing laparoscopic reduction gastroplasty. This also agrees with, G. Tusman et al., [15] who found no significant difference between groups concerning the $\mathrm{pH}$ and $\mathrm{PaCO} 2$.

In addition, SM. Asida et al., [17] studied the effect of low tidal volume during general anesthesia for urological procedures on lung functions. They compared the conventional mechanical ventilation using high tidal volume with zero PEEP and no recruitment maneuver with lung protective ventilation strategy using low tidal volume and $10 \mathrm{~cm} \mathrm{H} 2 \mathrm{O}$ PEEP. They found improved lung functions and arterial oxygenation intra and post-operative. This agrees with our results concerning the arterial oxygenation.

Moreover, in this study there was a statistical significant increase in the $\mathrm{PaO} 2$ at 5 minutes after desufflation in the low tidal volume (LTV) group compared to the conventional (C) group. However, (15) who studied the arterial oxygenation in three different groups (ZEEP, PEEP, Recruitment), reported that the $\mathrm{PaO} 2$ was increased in the PEEP group compared to its baseline but there were no inter-group differences in oxygenation between the PEEP and ZEEP group all through the surgery. Nevertheless, these results can be explained by their exclusion to the laparoscopic surgeries from the study because patients would be more prone to lung collapse and displacement of the diaphragm due to the insufflation that will definitely affect the oxygenation.

In conclusion, repeated recruitment maneuvers combined with $5 \mathrm{~cm} \mathrm{H} 2 \mathrm{O}$ of PEEP increased respiratory system compliance and $\mathrm{PaO} 2$ in patients undergoing laparoscopic surgeries without heamodynamics adverse effects. Moreover, the beneficial effects on oxygenation continued into the early recovery period.

\section{References}

[1] G .Hedenstierna, L .Edmark, The effects of anesthesia and muscle paralysis on the respiratory system. Intensive Care Med;Vol. 31, PP. 1327-35,2005.

[2] J .Sprung, DG. Whalley, T .Falcon, The effects of tidal volume and respiratory rate on oxygenation and respiratory mechanics during laparoscopy in morbidly obese patients. Anesth Analg;Vol.97, PP. 268-74,2003.

[3] V. Chalhoub, A. Yazigi, G. Sleilaty, Effects of vital capacity manoeuvres on arterial oxygenation in morbidly obese patients undergoing open bariatric surgery. Eur J Anaesthesiol; Vol.24, PP. 283-8,2007.

[4] WA .Almarakbi, HM. Fawzi, JA. Alhashemi, Effects of four intraoperative ventilatory strategies on respiratory compliance and gas exchange during laparoscopic gastric banding in obese subjects. Br J Anaesth;Vol.102(6), PP.862$868,2009$.

[5] FX. Whalen, O .Gajic, GB. Thompson, ML. Kendrick, FL. Que, BA. Williams, The effects of the alveolar recruitment maneuver and positive end-expiratory pressure on arterial oxygenation during laparoscopic bariatric surgery. Anesth Analg;Vol.102(1), PP.298-305,2006.

[6] CK. Pang, J. Yap, PP. Chen, The effect of an alveolar recruitment strategy on oxygenation during laparoscopic cholecystectomy. Anaesth Intensive Care;Vol.31(2), PP.176-180,2003.

[7] TN. Weingarten, FX. Whalen, DO. Warner, O. Gajic, GJ. Schears, MR. Snyder, Comparison of two ventilatory strategies in elderly subjects undergoing major abdominal surgery. $\mathrm{Br} \mathrm{J}$ Anaesth;Vol. 104(1), PP.16-22,2010.

[8] J .Fumagalli, RRS. Santiago, MT. Droghi, Lung Recruitment in Obese Patients with Acute Respiratory Distress Syndrome. Anesthesiology;Vol.130, PP.791803,2019.

[9] J .Sprung, FX. Whalen, T. Comfere, ZJ. Bosnjak, $\mathrm{Z}$.Bajzer, O .Gajic, Alveolar recruitment and arterial desflurane concentration during bariatric surgery. Anesth Anal;Vol.108(1), PP.120127,2009 .

[10] OS. Cakmakkaya, G. Kaya, F. Altintas, M. Hayirlioglu, B. Ekici, Restoration of pulmonary compliance after laparoscopic surgery using a simple alveolar recruitment maneuver. J Clin Anesth;Vol.21(6), PP.422-426,2009.

[11] S. Celebi, O. Koner, F .Menda, K. Korkut, K .Suzer, N .Cakar,The pulmonary and hemodynamic effects of two different recruitment maneuvers after cardiac surgery. Anesth Analg;Vol.104(2), PP.384-390,2007.

[12] HU. Rothen, P. Neumann, JE. Berglund, J .Valtysson,

Magnusson,G.Hedenstierna,Dynamics of reexpansion of atelectasis during general anaesthesia. Br J Anaesth;Vol.82(4), PP.551$556,1999$.

[13] C .Biddle, L. Epps, R. Hassanein, The efficacy of sighs in subjects with COPD undergoing general anesthesia and controlled ventilation. AANA J;Vol.57(2), PP.131-136,1989.

[14] P. Severgnini, G .Selmo, C. Lanza, A. Chiesa, A. Frigerio, A. Bacuzzi, Protective mechanical ventilation during general anesthesia for open abdominal surgery improves postoperative pulmonary function. Anesthesiology; Vol.118(6), PP.1307-1321,2013. 
[15] G. Tusman, SH. Bohm, GF. Vazquez de Anda, Alveolar recruitment strategy improves arterial oxygenation during general anaesthesia. $\mathrm{Br} \mathrm{J}$ Anaesth; Vol.82(1), PP.8-13, 1999.

[16] EE. Ahmed and AM. Abd el Hamid, The effects of alveolar recruitment maneuver and positive end expiratory pressure on arterial oxygenation and postoperative outcome in morbidly obese patients undergoing laparoscopic reduction gastroplasty. Ain-Shams Journal of Anaesthesiology; Vol.6, PP.129 133,2013.

[17] SM. Asida and MSh. Badawy. Effect of low tidal volume during general anesthesia for urological procedures on lung functions, Egyptian Journal of Anaesthesia.; Vol.31, PP.127-134,2015. 